\title{
A INSTITUIÇÃO DA RESERVA LEGAL NO CÓDIGO FLORESTAL BRASILEIRO: FUNDAMENTOS HISTÓRICO-CONCEITUAIS
}

Daniel Stella Castro ${ }^{1}$

Resumo: Fora do ambiente acadêmico, sobretudo nas arenas de debates relacionadas à agricultura, a Reserva legal ainda é percebida como futura área de conversão para a prática agrícola. Assim, este trabalho busca apresentar idéias e conceitos relacionados à instituição da Reserva Legal, com intuito de colaborar com as produções acadêmicas acerca da relevância do tema em questão. Por meio do método dialético realizou-se uma revisão $e$ sistematização bibliográfica desde o período colonial no Brasil até à inclusão do termo Reserva Legal no Código Florestal de 1965. Com a evolução das ciências naturais e mudanças de paradigmas, entre eles relativo à relação homem e natureza, no século XVIII, por exemplo, surge a teoria do dessecamento. Idéias e conceitos ligados a esta teoria possivelmente influenciaram os princípios estabelecidos no período da Regência por José Bonifácio de Andrade e Silva e, no início do século $X X$, os trabalhos acadêmicos e militância desenvolvidos por Albert Löefgren, acerca da institucionalização da regra de conservação de parte da propriedade rural com vegetação nativa.

Palavras-chave: Reserva legal; Desmatamento; Teoria do dessecamento.

\section{The Legal Reserve Institution in Brazilian Forest Code: Historical Conceptual Bases}

Abstract: Out of the academy, mainly inside agricultural political arena, the perception of the Legal Reserve still remains as a future area for convertion into agriculture practice. Thus this paper aims to present ideas and concepts related to Legal Reserve institution, in order to colaborate with the academic researchs due to the relevance of this theme. Through the dialetical method a bibliography revision was made since Brazilian colonial period to the inclusion of the term Legal Reserve in Brazilian Forest Code. Within the natural sciences evolution and the paradigms changing, such as human and nature relation, in eighteenth century for example was created the diseccation theory. Ideas and concepts related to this theory probably had influenced the principles of legal rules institution of native vegetation conservation inside private rural properties established by José Bonifácio de Andrade e Silva in the Regence period, and in the academic works of Albert Löefgren in the early of the twentieth century.

Keywords: Legal Reserve; Deforestation; Diseccation theory.

\section{INTRODUÇÃO}

Tanto no ambiente acadêmico como no externo, principalmente nos conjuntos sociais do setor rural brasileiro que tem na prática agrícola sua principal fonte de renda, inquirem-se as razões dos limites impostos pelo Código Florestal acerca das regras de conservação da

\footnotetext{
${ }^{1}$ Aluno de doutorado no Programa de Pós-graduação em Geografia Física do departamento de Geografia da Faculdade de Filosofia, Letras e Ciências Humanas da Universidade de São Paulo. E-mail: danielstellacastro@usp.br DOI: 10.7154/RDG.2013.0026.0007
} 
Reserva Legal (RL) em 80, 35 ou $20 \%$ da área de produção agrícola. Além disso, muito agricultores questionam a função ambiental da RL pautados no discurso de que a Área de Preservação Permanente (APP) já cumpriria tal aspecto. Estas argumentações, legítimas ou não, juntamente com outras enformaram o posicionamento dos parlamentares favoráveis à reforma da lei no 4.771 de 15 de setembro de 1965 (Código Florestal de 1965). Sobre a RL o principal objetivo no horizonte de interesses destes parlamentares era diminuir o tamanho das áreas de conservação e proteção dentro da unidade de produção agrícola, além da possibilidade de regularização da compensação do passivo ambiental em áreas distantes do local desmatado ilegalmente, inclusive em outros estados da federação. Foi aprovado tanto na câmara como no senado federal, além de ratificado pela presidente o segundo item.

De qualquer maneira, à parte da discussão existente sobre a interpretação, visibilidade ou disponibilidade ao público interessado nos trabalhos acadêmicos, tema muito caro aos serviços de extensão das faculdades, sobretudo das instituições públicas, neste ambiente acadêmico é pública a informação de que existem vários trabalhos científicos demonstrando a necessidade da dimensão mínima de áreas com vegetação natural ou regenerada para a sobrevivência de diversas espécies, entre mamíferos, répteis, aves, a própria flora etc. Dentre vários, chama-se atenção para os estudos de Whitmore e Sayer (1992) e Pardini et al. (2010) sobre fragmentação florestal e seus impactos negativos na biodiversidade, Mahar (1989) cuja pesquisa aborda os limites mínimos em extensão da cobertura vegetal natural para a sobrevivência de determinadas espécies da fauna, Rocha (1996) relacionando o efeito da retirada da cobertura vegetal natural em relação ao regime pluviométrico da região amazônica, ou num mais recente, em que Santiago (2005) por meio de modelagem matemática observou a conservação de um maior volume de água no sistema solo-plantaatmosfera da bacia do rio Ji-Paraná, em Rondônia, quando o solo é recoberto por floresta, em relação aos solos recobertos por pastagem ou soja. Estes trabalhos demonstram algo bem diferente do que foi aprovado na reforma do Código Florestal de 1965.

Deve-se também destacar Metzger (2001, 2010), onde demonstra os limites mínimos necessários para conservação da RL na Amazônia Legal e, em outro artigo recente, rediscute as bases científicas que pautaram suas assertivas, como a teoria da percolação e o conceito de limiar de fragmentação, além de afirmar que os limites fora da Amazônia Legal deveriam ser maiores que $20 \%$, não considerando a APP no cômputo da RL.

Há também um corpo de trabalhos específicos sobre APP acerca de vegetação de topo de morro e em ambiente marginais a cursos d'água, podendo ou não sofrer inundações 
conforme os diferentes regimes hídricos, em que buscam apresentar e demonstrar uma extensão mínima de faixa marginal recoberta por vegetação nativa (CASATTI, 2010; DEVELEY; PONGILUPPI, 2010; GALETTI, M. et al.; RIBEIRO; FREITAS, 2010).

Entretanto, ao nos depararmos com as multiplicidades de paisagens existentes no território brasileiro, evidencia-se que a relação homem e espaço reflete diversas realidades podendo ser percebidas e descritas ${ }^{2}$, seja em ambiente urbano ou rural. Pragmaticamente, isto apontaria à uma lógica de criação de regras gerais para organização das relações sociais em um dado espaço considerando tais diversidades nele inscritas. Neste sentido, torna-se inviável equalizar a dimensão da área a ser conservada como RL para todo o Brasil, ou para extensas porções de seu território, mesmo sabendo, como demonstram as pesquisas científicas, que não existem gradações ou hierarquizações entre tais espaços a serem mais ou menos conservados ou preservados segundo suas especificidades e relações entre as formações vegetais e flora, fauna, clima, solo. Evidente que onde há extensas áreas ainda não alteradas ou transformadas pelo modo de produção capitalista, e isto não se restringe somente às fitofisionomias florestais, mas também aos cerrados e outras possíveis vegetações presentes nas paisagens brasileiras, deve-se manter os esforços por meio de políticas públicas para proteção delas. Porém, isto não significa que as regras de conservação devem ser muito distintas ou distantes das anteriores paras as áreas com maior grau de alteração da paisagem em função das ações humanas.

Portanto, em função do evidente confronto existente no contexto do atual debate sobre o novo Código Florestal, principalmente realizado pelos pensamentos da classe dos grandes produtores agrícolas e latifundiários com os da classe acadêmica (pelo menos uma fração desta), optou-se pelo método dialético com intuito de estruturar e construir no presente trabalho uma resposta à percepção e afirmação proveniente da classe dos latifundiários e grandes agricultores e, sobretudo, que a criação da Reserva Legal tem bases científicas, legitimando e localizando apropriadamente sua importância no contexto do atual debate do novo Código Florestal. Assim, segundo o entendimento do método dialético elucidado por Menezes (1966) e Sposito (2004), que apresentam algumas noções presentes nos pensamentos de Heráclito, Platão, Aristóteles, Sócrates chegando até a dialética em Hegel, acredita-se que com tal resposta seja possível apontar à classes sociais envolvidas que apesar de suas diferenças ideológicas e práticas, localizam-se dentro de uma mesma identidade no que tange a discussão sobre a Reserva Legal e a eficácia do Código Florestal.

${ }^{2}$ Considera-se o conceito de paisagem formado pelas noções do seu suporte material (relacionado ao geosistema e ecosistema que sofre intervenção do homem) e de seu imaginário (sua percepção e descrição pelos homens) (ROUGERIE, BEROUTCHACHVILI, 1991). 
Neste sentido utilizando o procedimento de revisão bibliográfica por meio das palavras chave Instituição do Código Florestal, Instituição da Reserva Legal ou Reserva Florestal, Conservação florestal, Instituições ambientai e, Ecologia política, o esforço neste artigo tem como principal objetivo apresentar ideias e conceitos que fundamentaram ou buscaram sedimentar a noção sobre a importância da conservação da vegetação nativa em área de produção agrícola e que tenha relação com a criação da RL.

\section{A evolução temporal da preocupação ambiental}

A preocupação em cuidar ou conservar o meio em que um determinando grupo social vive e extrai seus recursos para manutenção do seu modo de vida pode ser rastreada até a antiguidade grega, por exemplo, analisando-se alguns escritos de Platão acerca da devastação de florestas, solos degradados e erodidos como conseqüência de uma intensa agricultura praticada por meio do sistema agrário vigente na época (GROVE, 1995; MAZOYER e ROUDART, 2001; MAGALHÃES, 2002). Grove (1995) assevera que o receio acerca das alterações climáticas em função das ações humanas é relatado nos documentos de Theophrastus da Erasia, botânico e biógrafo de Aristóteles, que observou e descreveu em sua obra Historia Plantarum a existência de relação entre o desmatamento com a diminuição pluviométrica que ele acreditava ocorrer na Grécia.

Documentos históricos relatando a instituição de regras referentes à conservação dos recursos florestais, como a criação de Reservas Florestais, remonta o surgimento dos antigos impérios na área da Mesopotâmia central, cerca de 1700 anos a.C. Em 117 e 138 d.C, durante o império romano, reservas florestais foram instituídas na região norte das montanhas libanesas. No fim da idade média e início da moderna, dentre vários exemplos, destaca-se a proteção das florestas de Nürmberg na Alemanha $^{3}$ e o reflorestamento das margens dos cursos d'água ordenado em 1450 pelo império veneziano após perceber o assoreamento dos rios provocado pelo constante acúmulo de silte e, sobretudo, pela extrema redução da oferta de madeira em virtude do escasseamento dos recursos florestais. Diversos outros relatos do passado concernentes à ação humana no ambiente poderiam ser reinterpretados de acordo com a atual noção da corrente de pensamento sobre conservação ambiental. No entanto, vale lembrar que "[a noção do] que hoje denominamos de meio ambiente não existia há duzentos anos [...]. Não havia 'destruição do meio ambiente',

${ }^{3}$ Nürmberg Royal Forest. Entre 1289 e 1310 foi ordenado o reflorestamento das margens do rio Pegnitz, amplamente utilizada pela prática agrícola. 
embora já existisse sem dúvida quase tudo o que hoje entendemos por essa expressão." (TREPL, 2002, p. 329). A atual noção sobre o ambiente é distinta da compreendida há praticamente dois séculos e meio (TREPL, 2002).

De qualquer forma, adaptando o termo atual aos fatos do passado pode-se aproximar que as crises ambientais são questões assaz antigas, as quais o homem procurou solucionar, calcado basicamente em duas concepções filosóficas que ele fez de si mesmo acerca da sua percepção do espaço, neste caso, da natureza e de sua posição nela. Neste sentido, a natureza pode ser entendida como "uma entidade da qual o homem está ausente [...] [e a outra onde] o homem é considerado parte integrante da natureza, da qual é originário e que ele transforma" (ACOT, 1992, p. 7).

O conceito de natureza no pensamento ocidental foi influenciado pela fusão da corrente filosófica grega e da religião cristã. Dito de outra forma, a relação do homem e natureza é influenciada pelos processos de helenização, romanização e europeização, refletindo na maneira como as sociedades das ex-colônias européias ocidentais percebiam e, de certa forma, ainda percebem a natureza ${ }^{4}$.

Com a evolução das ciências naturais e mudanças de paradigmas, entre eles relativo à ação do homem na natureza, a partir da segunda metade do século XVII uma coerente e relativa preocupação sistematizada se desenvolveu acerca das mudanças no ambiente geradas pela exploração dos recursos naturais. Neste sentido, cita-se a instituição de leis de proteção das águas e florestas na França em 1689 como reflexo da grande exploração de seus recursos florestais, entre elas as Leis de Colbert que perduraram por oito anos restringindo o corte de árvores das reservas florestais, além de exigir que o proprietário de terra plantasse mudas de árvores em 5\% de sua área. (GROVE, 1995; LEÃO, 2000; MAGALHÃES, 2002).

Esta preocupação ambiental foi instilada no decorrer dos anos como resultado de uma ação específica e ecologicamente destrutiva da expansão comercial das Companhias Holandesas e Inglesas das Índias Orientais e posteriormente da Companhia Francesa das Índias Orientais (GROVE, 1995) ${ }^{5}$. Deste modo, a ideologia conservacionista resultante deste período congrega uma nova forma de avaliação da natureza tropical ${ }^{6}$, pautada em diversos trabalhos empíricos da geografia das ilhas localizadas nas costas do continente Africano e Asiático e a descrição da fauna e flora delas. Porém, as práticas conservacionistas deste período

\footnotetext{
${ }^{4}$ No século XX deve-se considerar também o desenvolvimento das correntes de pensamentos norte-americanas.

${ }^{5}$ Provavelmente também como reflexo da ação das Companhias das Índias Ocidentais das supracitadas nações, porém os desdobramentos dos processos de ocupação e exploração das Américas, especificamente a Latina, não são enfocados na obra de Grove (1995).

${ }^{6}$ Aqui o autor refere-se aos recursos naturais localizados entre os trópicos de Capricórnio e Câncer, lógica que no século XX influenciou a construção do termo Floresta Tropical, fruto do movimento de ecologia política. (SMOUTS, 2003).
} 
dificilmente poderiam ser reconhecidas como idéias distintas na complexa teia dos arranjos econômicos, religiosos e culturais desenvolvidos a partir de múltiplas sociedades com intuito de resguardar e sustentar seus acessos aos recursos naturais (GROVE, 1995).

\section{Teoria do Dessecamento ${ }^{7}$}

Com o surgimento das teorias climáticas na segunda metade do século XVIII e a emergência de uma corrente teórica que buscava relacionar o desmatamento com os efeitos climáticos e atmosféricos, intitulada de dessecamento ${ }^{8}$, uma nova importância foi dada à questão da apropriação dos recursos naturais. Este distinto discurso estava ligado às pesquisas agronômicas que defendiam a conservação de bosques como reguladoras da erosão do solo e do aspecto físico e químico dele, bem como o uso de práticas sistematizadas de manejo florestal para extração da madeira (GROVE, 1995).

A fundação da Royal Society e a Académie des Sciences foi fundamental para a formação de importantes teorias climáticas, inclusive a do dessecamento. Grove (1995) justifica a emergência de tais teorias e sua permanência como dominantes neste período pelo fato de estarem alinhadas aos ideais de agrônomos e outros profissionais filiados à corrente fisiocrática do iluminismo francês, que na época estava em evidência e fomentava os debates e a difusão nas academias dos conhecimentos relativos às observações e estudos empíricos desenvolvidos principalmente em suas colônias insulares. De qualquer maneira, no período mencionado anteriormente, havia muitas incertezas e questionamentos sobre o modelo econômico vigente. Assim, uma destacada consciência, sobretudo acadêmica, desenvolveu uma crítica visão sobre o modo de vida nas sociedades europeias da época, inclusive sobre o padrão predatório de apropriação e usos dos recursos naturais.

As colônias insulares serviram como bons "canteiros experimentais" na observação das mudanças do regime de chuvas, abastecimento de água para irrigação agrícola e consumo doméstico. As teorias climáticas da época impulsionavam-se como formas de repostas à rápida transformação ecológica nas colônias e ao aumento dos interesses da medicina sobre os fatores que afetavam a saúde e as doenças nas áreas de clima tropical. Neste contexto, a teoria do dessecamento tornou-se claramente ligada ao desenvolvimento da medicina tropical. Aproxima-se que a noção de circulação atmosférica recebeu influências dos estudos

\footnotetext{
${ }^{7}$ Na língua inglesa esta palavra é apresentada por Grove (1995) como desiccation.

${ }^{8}$ Discurso ligado às teorias climáticas com base nos princípios newtonianos difundidos na época, esta corrente de pensamento foi desenvolvida por ingleses e aperfeiçoada por franceses durante os séculos XVII e XVIII.
} 
acerca do funcionamento do sistema circulatório sanguíneo combinadas com a teoria newtoniana. Nesta corrente destacam-se John Woodward e Stephen Hales, formadores das bases para o desenvolvimento da teoria do dessecamento, aperfeiçoada por Pierre Poivre and Joseph Priestley (GROVE, 1995).

Woodward realizou pesquisas sobre fisiologia de plantas, estudando aspectos sobre nutrição e transpiração, publicando estes ensaios em $1699^{9}$. Também fez observações relacionando umidade do ar com recobrimento do solo por árvores. Basicamente em seus ensaios ele se preocupava com as taxas de mudança ambiental no decorrer do tempo e influências ambientais em doenças e extinção de espécies. Contudo, as pesquisas de Woodward sobre as plantas e suas relações com a atmosfera não tiveram um tratamento estatístico, mecânico ou fisiológico que permitisse a replicação de seus ensaios por outros cientistas (GROVE, 1995).

Stephen Hales, discípulo de Newton, apropriando-se dos estudos de Woodward publicou em 1727 uma obra intitulada Vegetable Staticks onde quantifica e enfatiza as relações entre vegetação e atmosfera, além de implicitamente apontar para a possibilidade de interferência na constituição atmosférica pela ação humana.

Neste período o Estado francês enviava cientistas para serem treinados na Inglaterra. Desta fase destacam-se Georges-Louis Leclerc (Conde de Buffon) e Henri-Louis Duhamel du Monceau, pertencentes à corrente fisiocrática e que pautaram-se diretamente nos estudos de John Woodward e Stephen Hales sobre fisiologia de plantas. Conde de Buffon, além de traduzir a obra Vegetable Staticks, estudou a relação entre vegetação e composição atmosférica, posteriormente aprofundada por Duhamel du Monceau, desenvolvendo diversos trabalhos em que descreve as relações entre a taxa de crescimento da vegetação com a precipitação. Cabe ainda salientar que Conde de Buffon era o chefe do Jardin du Roi, onde trabalhou também Duhamel du Monceau (GROVE, 1995).

Dentre os seguidores do rigoroso empiricismo científico associado ao lluminismo botânico francês e influenciados pelos trabalhos de Conde de Buffon e Duhamel du Monceau, Grove (1995) considera Pierre Poivre, Philibert Commerson e Bernardin de Saint-Pierre como os precursores das correntes do ambientalismo moderno com o surgimento de políticas ambientais. Esta corrente de pensamento além de influenciada pelos trabalhos sobre teorias climáticas desenvolvidas pelos cientistas citados anteriormente também se estruturou,

\footnotetext{
9 J. Woodward, 'Some thougths and experiments concerning vegetation', Philosophical Transaction of the Royal , Society, 21, (1699), 196227; repr. In E. Halley, ed., Miscellanea Curiosa, vol. I, London, 1708, p. 230-30. apud GROVE, R. H. Green Imperialism: colonial expansion, tropical islands edens, and the origins of environmentalism, 1600-1860. 540p. 1995.
} 
sobretudo, pela sistematização das observações dos impactos negativos decorrentes da ação antrópica nos ambientes das colônias insulares.

Tanto na França quanto na Inglaterra o debate sobre os impactos de atividades de produção, principalmente agrícola, deste período atingiu seu clímax influenciado por estudos realizados nas ilhas Maurício. Entre 1769 e 1810, sob administração francesa e com representantes da corrente fisiocrática influenciando diretamente no gerenciamento das ilhas, foi estabelecido um dos primeiros experimentos em ambiente insular (registrado historicamente) sobre sistemas de conservação florestal, controle de poluição de águas e regulação da atividade pesqueira, período no qual Pierre Poivre administrou as ilhas Maurício. Certamente as bases científicas da teoria do dessecamento, desenvolvida na Inglaterra, e a atuação de Pierre de Poivre na academia francesa colaborou com a instituição de medidas de proteção florestal nas ilhas Santa Helena e no Caribe e na conservação florestal das ilhas Maurício. Tais medidas serviram de referência para o manejo e conservação das florestas das outras colônias francesas e inglesas durante o período da expansão comercial marítima (GROVE, 1995).

\section{A conservação de reservas florestais para extração de madeira}

Assim como a busca de resolução e intervenção do Estado Francês e Inglês por meio da criação de políticas de proteção de suas florestas para garantia da extração da madeira desde a segunda metade do século XVIII, o modelo luso-espanhol também passou a impor medidas reguladoras para exploração madeireira em suas colônias. Entrementes, a prática agrícola itinerante na América portuguesa e espanhola provocou diferentes impactos ambientais, sendo mais severos e possivelmente irreversíveis, sem intervenção por meio de plantio de espécies nativas e sua manutenção, em algumas regiões de ocupação portuguesa mais antigas no Brasil, como em certas porções do nordeste brasileiro (PEREIRA, 1950; DEAN, 1996).

Em 1605 a coroa luso-espanhola criou o serviço de guardas florestais para implementar tais regulamentações, que dependendo do ato de infração, poderia ter punições extremas, inclusive a pena de morte (MAGALHÃES, 2002). Interessante notar que em 1681 no Brasil havia uma política do governo português de que nenhum engenho de cana-de-açúcar poderia estabelecer-se a menos de meia légua $(3,3 \mathrm{~km})$ de outro, para que a reserva florestal de cada engenho fornecesse a quantidade suficiente de lenha ao seu funcionamento. Aqui 
fica bem clara a noção de uma reserva florestal como área destinada ao fornecimento de madeira para a geração de energia nos engenhos.

Em 1698, a coroa portuguesa instituiu a proibição de sesmarias em áreas com árvores de valor para indústria madeireira, além de uma série de leis que restringiram a exploração dos recursos florestais. Assim, o sesmeiro necessitava de autorização régia para exploração florestal e uso comercial das madeiras de valor para o setor na época ${ }^{10}$. Aqui fica clara a intenção da coroa na manutenção de seu monopólio sobre as madeiras de importância comercial. Não obstante, estas regras expressaram pouca eficácia seja pelo desinteresse dos fiscais, seja pelas vicissitudes financeiras enfrentadas pelos colonos em função das dificuldades em desenvolver outras formas de renda.

Apesar da relação da conservação da cobertura vegetal em encostas com a manutenção da estrutura do solo nestas áreas, é evidente que até então foi a lógica econômica o princípio indutor das políticas de proteção dos recursos florestais. Em 1800 a coroa portuguesa expediu uma carta régia proibindo o corte de madeira em terras particulares numa largura de 10 léguas da costa marítima (SWIOKLO, 1990).

Referente às ideologias que se aproximavam das práticas de proteção ambiental, a aristocracia portuguesa e a igreja consideravam subversivas as concepções políticas e sociais do lluminismo. Mesmo assim, tais ideias acabavam de alguma forma influenciando as academias portuguesas por meio de intercâmbios de alunos, mas sobretudo de professores. No Brasil, antes da chegada da família real, além dos seminários não havia instituições de ensino superior, gráficas e bibliotecas públicas (DEAN, 1996). Contudo, fruto de brasileiros que se graduaram na Europa, muitos em Portugal, e do intercâmbio com outros cientistas naturais europeus, iniciou-se um movimento de estudos acadêmicos influenciados por uma mentalidade científica moderna, como as teorias climáticas da época e outros reflexos do Iluminismo acerca de questões sociais e políticas. Desta herança de brasileiros intelectuais, muitos foram influenciados pelos ensinamentos de Domenico Vandelli, naturalista italiano contratado pela coroa portuguesa em 1764 sob recomendação do Marquês de Pombal para auxiliar na reforma curricular da Universidade de Coimbra. Vandelli que recebera influência dos estudos de Georges-Louis Leclerc (Conde de Buffon) e Henri-Louis Duhamel du Monceau, difundiu em Portugal uma corrente científica conhecida como economia da natureza, que seria o estudo da natureza para fins econômicos, observando e resguardando

\footnotetext{
${ }^{10} \mathrm{O}$ termo madeira-de-lei, na origem, relaciona-se ao fato da manutenção do monopólio da coroa portuguesa sobre as madeiras de interesse ao setor, na época, sobretudo o naval. Assim, o colono necessitava de autorização régia para extração de tais madeiras, pois em princípio, no período colonial, todo território pertencia à coroa portuguesa.
} 
seus limites naturais (DEAN, 1996; RESENDE, 2006). Assim, evidencia-se um destacamento de uma lógica ecológica da corrente econômica dominante.

Entre os cientistas brasileiros educados em Portugal e que realizaram trabalhos de destaque no Brasil criticando o modelo exploratório dos recursos naturais, destacou-se Alexandre Rodrigues Ferreira, discípulo direto de Vandelli e que produziu a obra Viagem Filosófica, na qual repreendeu a destruição dos recursos naturais amazônicos (PÁDUA, 2005).

No século XVIII e XIX vários cientistas (naturalistas) estiveram no Brasil, como Charles Darwin, Alexander Von Humboldt ${ }^{11}$ e Eugenius Warming ${ }^{12}$. Humboldt e Warming deixaram grandes contribuições dos seus trabalhos ao desenvolvimento de estudos relacionando fauna, flora e clima, cujas informações colaboraram com a fundamentação de alguns conceitos da Ecologia (ACOT, 1996).

Com a presença da corte portuguesa no Brasil desencadeou-se a criação de uma série de instituições, inclusive de cunho científico. Foram estabelecidas gráficas, bibliotecas, uma escola de medicina, laboratório de análises químicas, uma cátedra de ensino agrícola em Salvador, o Jardim Botânico no Rio de Janeiro e uma academia militar designada ao ensino de engenharia civil e mineração. Este marco criou um ambiente propício para o fortalecimento de intercâmbios com institutos europeus, no intuito de fomentar o conhecimento dos recursos naturais brasileiros, suas potencialidades comerciais e a adaptação de espécies vegetais com possibilidades de cultivo em escala comercial. Deste período destacam-se também Karl Friedrich Philipp von Martius, August de Saint-Hilaire, Johan Emanuel Pohl, que na sua passagem em 1818 pelo Rio de Janeiro descreveu a existência de diversas plantas exóticas de origem asiática cultivadas no jardim botânico, entre elas a soja (Glicine max) (DEAN, 1996).

José Bonifácio em 1802, como Intendente Geral de Minas e Metais do Reino, recomendou o reflorestamento do litoral do Brasil, especialmente em áreas já decretadas como parques destinados às reservas florestais, o que foi instituído formalmente pelo Governo (SWIOKLO, 1990). Na Regência, como conselheiro do imperador, participou da promulgação de uma legislação sobre o uso do solo em 1823, prevendo a manutenção da cobertura vegetal nativa em um sexto da área da propriedade privada que fora vendida ou doada pela Coroa. Este comportamento conservacionista de José Bonifácio acredito que tenha origem na sua formação em Geologia pela Universidade de Coimbra, onde certamente recebeu influência

\footnotetext{
${ }^{11}$ Humboldt iniciou sua jornada na América Latina em 5 de janeiro de 1799 , percorrendo 15.000 km, sendo aproximadamente 2.500 km por redes fluviais, passando pelo rio Negro e Amazonas (ACOT, 1996).

12 Eugenius Warming entre 1863 e 1866 produziu uma importante obra a respeito do Brasil Central, pautado em seus estudos de classificação de grupamentos vegetais (ACOT, 1996).
} 
da corrente de pensamento de Vandelli e, posteriormente em Silvicultura em Brandemburgo, que o habilitou a prestar serviços como diretor de reflorestamento da costa portuguesa até a época da invasão francesa (DEAN, 1996).

Curiosamente, neste período diversas restrições foram instituídas para o corte de algumas espécies vegetais, bem como sobre o manejo de áreas com vegetação nativa. Assim, em 1825 reiterou-se a proibição de expedição de licenças para corte do pau-brasil em propriedades privadas; Em 1829 foram reafirmadas as proibições quando não havia autorização da câmara municipal para derrubar e roçar a vegetação em terras devolutas; Em 1830 foi promulgado o Código Criminal que já continha entre seus artigos penalidades para a extração ilegal de madeira (KENGEN, 2001). Não obstante, em 1831 tais regras foram extintas e, em 1834 o monopólio imperial sobre extração do pau-brasil foi revogado (SWIOKLO, 1990; KENGEN, 2001). Para Kengen (2001) a eliminação destas normas deu o impulso que faltava para o aumento da degradação dos recursos florestais, principalmente na região litorânea e próximo aos centros urbanos.

No campo do desenvolvimento dos estudos acadêmicos no Brasil, Dean (1996) cita como principais instituições desta época a Sociedade Auxiliar da Indústria Nacional (1825); Instituto Histórico e Geográfico Brasileiro (1838); Núcleo Imperial de Horticultura Brasileira (1849); Sociedade Vellosiana (1851); Sociedade Agrícola Fluminense (1854); Instituto Imperial Fluminense de Agricultura (1860). Formaram-se outras sociedades concernentes à racionalização do uso sistematizado dos recursos naturais que publicaram artigos calcados em conceitos ecológicos. Entretanto, a influência das classes latifundiárias do país sempre se fizeram prevalecer em momentos oportunos de definição e ampliação dos seus direitos de propriedade, pois sua representação política no seio do Estado sempre foi maior. Neste sentido, em 19 de julho de 1876 a extração legal de madeiras de lei em florestas privadas não exigia mais licença expedida pelo governo (SWIOKLO, 1990).

A crença que o desmatamento dos mananciais supridores de água provocaria o secamento das nascentes e consequentemente afetando o abastecimento da sociedade fez com que o Governo Imperial, tanto em São Paulo como no Rio de Janeiro realizasse a primeira tentativa de implementar práticas conservacionistas para garantir o bem-estar social. Portanto, em 1862 iniciou-se a recomposição da floresta da Tijuca e em São Paulo, em 1889 quando Albert Löefgren assumiu o Serviço Florestal e Botânico do Estado, foi decretada a primeira reserva de floresta pública estadual na Serra da Cantareira. Acredito que tal crença estava pautada ou ao menos influenciada por uma lógica ligada à teoria do dessecamento. 


\section{A emergência de políticas conservacionistas de cunho não econômico/utilitarista}

Segundo Swiolko (1990), mesmo com a proclamação da República e, conseqüentemente, o estabelecimento de um ambiente de mudança institucional, todo o aparato de regras formais para a regulação dos recursos florestais vigorava de acordo com as leis do período anterior, sem contar que o poder das classes latifundiárias sobre as terras estaduais havia aumentado. "A constituição promulgada em 1891 transferia para os estados as terras públicas anteriormente pertencentes ao governo central" (DEAN, 1996, p. 229). Magalhães (2002) ainda afirma que a primeira Constituição da República não continha sequer uma linha com referência à proteção ambiental. Por outro lado, institutos que outrora surgiram para solucionar os problemas demandados pelos grandes produtores rurais, como o Agronômico de Campinas, passaram para a administração pública, reduzindo, mesmo que parcialmente, a interferência dos interesses das classes latifundiárias nos trabalhos e pesquisas científicas. Esta mudança na trajetória dos trabalhos científicos viabilizou o crescimento de estudos fundamentados em conceitos ecológicos, desvinculados de questões exclusivamente econômicas/utilitaristas (DEAN, 1996).

Dentre diversos cientistas dos institutos públicos filiados à nova tendência das pesquisas no Brasil, Dean (1996) destaca a atuação de Albert Löefgren, botânico sueco que fora contratado para dirigir as seções de Meteorologia e Botânica da Comissão Geológica e Geográfica brasileira. Nesta atividade Löefgren realizou coletas de espécies vegetais nativas, aclimatou espécies vegetais exóticas, organizou herbários e publicou estudos demonstrando a relação do desmatamento com as alterações climáticas, recomendando o reflorestamento por meio de espécies nativas como solução necessária à mitigação de tal efeito. Pode-se afirmar que ele corroborou a teoria do dessecamento.

As argumentações do botânico sueco, mesmo pautadas cientificamente, encontravam imensa resistência nas classes dominantes ligadas à agricultura, pois ele defendia a organização e implementação de uma política nacional de conservação dos recursos florestais. Para tais classes, a manutenção do estado de desordem sobre a regularização das terras públicas, devolutas e privadas - que Löefgren considerava como um importante fator do desmatamento desordenado - contribuía com a possibilidade de aumentar a extensão de suas propriedades, bem como a aquisição de novas áreas, processo que curiosamente perpetua hodiernamente, por exemplo, na porção norte brasileira. No período de Löefgren 
são numerosos os relatos de práticas ilegais que legitimaram direitos de propriedades sobre terras públicas e da expropriação de terras privadas. Uma das mais relatadas foi a grilagem de terras (DEAN, 1996).

Löefgren procurou sensibilizar a opinião pública por meio da publicação de artigos de sua autoria em jornais paulistas sobre a degradação ambiental causada pelo desmatamento desordenado. Adicionalmente, promoveu ações para as companhias ferroviárias criarem suas próprias reservas florestais, na tentativa de dirimir a pressão sobre as florestas nativas. A celebração do dia da árvore no calendário brasileiro é de sua autoria.

Nesta época, o Estado de São Paulo, Paraná, Minas Gerais e Rio de Janeiro iniciaram suas discussões sobre a criação de leis estaduais que regulassem o uso dos recursos florestais e, em 1904, por meio da Lei no 706 de 10 de abril, o Paraná institui seu Código Florestal. No entanto, nesta lei não há artigo que faça referência à restrição do uso dos recursos florestais em propriedade privada (CARVALHO, 2007).

O tipo de sistema agrário deste período, de maneira geral, conservava a reserva florestal dentro da propriedade rural como fonte fornecedora de madeira para uso doméstico, uso no próprio sistema de produção (cercas, ferramentas, cochos etc.), fornecimento de lenha e fertilizantes para o solo ${ }^{13}$. Löefgren, profundo conhecedor deste sistema e do manejo agrícola praticado na época, concluiu que seria mais eficaz promover junto aos produtores rurais a proteção dos remanescentes florestais privados, enquanto não se alterava o estado de inércia nos órgãos responsáveis do Estado para a criação e aprovação da regulamentação de regras para proteção dos recursos florestais privados. Neste sentido, vale destacar sua argumentação:

Sendo a área das propriedades particulares muito superior á das propriedades do Estado, principalmente na parte mais povoada e atravessada pelas grandes vias de communicação, a conservação das florestas é atividade de grande importância não somente como fator importante de fortuna publica e privada como igualmente para as condições climatericas, hygienicas e hydrographicas [...] Mas, estando ainda para organizar-se o serviço florestal por parte do Estado, o que certamente ainda demorará algum tempo, não há motivo nenhum para que o proprietário particular, zeloso da sua fortuna e dos seus interesses, não o inicie desde já nos seus terrenos, e é para isso que queremos fornecer algumas bases e indicações relativamente aos methodos mais práticos e economicos para o melhor aproveitamento das mattas existentes, na sua conservação e melhoramento, ou para creação de novas em logares onde isso se torna desejável ou vantajosa. (Löefgren, 1903, p. 3).

\footnotetext{
${ }^{13}$ Este sistema agrário, segundo Mazoyer e Roudart (2001), é classificado como o de cultura atrelada pesada sem pousio, no qual, de maneira geral, a propriedade está repartida em quatro áreas, uma delas destinada ao campo natural e cobertura florestal, três quartos para a prática agrícola.
} 
Neste período, o eucalipto (Eucalyptus globulos) estava aclimatado e experimentado para plantios em escala comercial no Brasil, inclusive recomendado por Löefgren, além da Acacia decurrens, quando o objetivo era o reflorestamento para a produção de madeira. Löefgren, além do reflorestamento para produção de madeira por meio do monocultivo com espécie exótica, sugeria também o plantio da espécie nativa Pau-jacaré preto (Piptadenia communis), ou através de outro manejo, o policultivo, contemplando espécies nativas com uma exótica de crescimento rápido para fornecimento da madeira, enquanto as nativas de crescimento lento atingiriam o ponto ideal para o corte.

Em 1905, Löefgren propôs ao governo do estado de São Paulo que se decretasse a área do Pontal do Paranapanema como Reserva Florestal, no intuito de conservar o imenso maciço florestal existente nesta porção do estado. Todavia, sua sugestão não foi $\operatorname{acatada}^{14}$ e, curiosamente, de acordo com Magalhães (2002), em 1911 criou-se a primeira reserva florestal federal no antigo território do Acre recobrindo praticamente toda sua área. Ainda em 1911 Edmundo Navarro de Andrade ${ }^{15}$ passa a ocupar o cargo de Löefgren no Serviço Florestal e Botânico, favorecendo a disseminação das plantações de eucalipto por grandes extensões no Estado de São Paulo, inclusive substituindo áreas de florestas nativas (DEAN, 1996). O posicionamento de Navarro era menos ligado à conservação do que à produção de madeira, refletindo a demanda econômica das classes latifundiárias e diretamente das companhias ferroviárias.

Contemporâneos de Albert Löefgren e seus predecessores contribuíram para a consolidação de uma geração de novos cientistas estabelecidos em cargos públicos atuando a favor da proteção dos recursos naturais, pressionando a criação de uma legislação federal que atendesse tais questões, principalmente em terras privadas. Dean (1996) destaca a ação de Lourenço Baeta Neves, Ary Fontenelle e Alberto José de Sampaio e Hoehne (na época diretor do Instituto Botânico de São Paulo). Pode-se também ressaltar a atuação de algumas organizações, são elas: Sociedades Amigos de Alberto Torres; Clube de Amigos da Natureza; Sociedade Geográfica do Rio de Janeiro; Sociedade Amigos da Árvore (fundada em 1931 por Alberto José de Sampaio); Sociedade Amigos da Flora Basílica; Sociedade dos Amigos do Museu (organizada por funcionários do Museu Nacional).

Portanto, com estas organizações demonstra-se que a ideologia conservacionista também atingiria outros grupos e classes. Como reflexo do protesto da sociedade em relação ao

\footnotetext{
${ }^{14}$ O Pontal do Paranapanema foi decretado como Reserva Florestal em 1941 (DEAN, 1996).

${ }^{15}$ Em 1904, exercendo a função de Presidente da Companhia Ferroviária Paulista, Antônio Prado, ex-ministro da Agricultura, contratou Edmundo Navarro de Andrade para implantar a reserva florestal da empresa (DEAN, 1996).
} 
desmatamento no Rio de Janeiro, em 1934 foi realizada a primeira conferência brasileira sobre a proteção da natureza. Neste evento foram analisados desmatamentos das florestas de cada estado. Por conseguinte, o governo Vargas criou políticas públicas que cerceassem as demandas conservacionistas de parte da burocracia estatal, porém sem alterar os interesses políticos do seu governo. De qualquer maneira, entre 1933 e outubro de 1934 ocorreram expedições científicas e a instituição de uma série de leis acerca do uso da água, dos minerais, da fauna e da flora, surgindo assim o primeiro Código Florestal Brasileiro com o do decreto no 23.793, de 23 de janeiro de 1934 (SWIOKLO, 1990; DEAN, 1996; MAGALHÃES, 2002).

\section{O Código Florestal de 1934}

A corrente de pensamento de proteção ambiental não era predominante no governo ${ }^{16}$, sendo hercúleo o esforço dos agentes públicos para garantir o cumprimento do Código Florestal (DEAN, 1996). O relato de Luciano Pereira da Silva, relator do anteprojeto do Código Florestal de 1934, ilustra este período:

A inércia, por displicência das autoridades estaduais e municipais, quando não resistência passiva e deliberada, encontra explicação na mentalidade dominante do país, incapaz de compreender até hoje que a deflorestação de terras públicas é um mal de terríveis conseqüências para as regiões onde é praticado. Mas se essa é a lamentável realidade oferecida pelos que governam ou administram que se presume saírem das elites locais, mesmo constituídos os conselhos, nem por isso ficam interessados seus membros em dar cumprimento aos dispositivos do Código, continuando como dantes as florestas que deveriam ser declaradas protetoras ou remanescentes, por sua localização, entregues ao machado e ao fogo, mesmo quando revestindo terras ainda devolutas ao patrimônio do estado e municípios. (SWIOKLO, 1990, p. 55).

O Código Florestal de 1934 instituiu que o proprietário rural ao desmatar sua área deveria resguardar um quarto dela com cobertura florestal nativa. Além disso, classificou as florestas em protetoras, remanescentes, modelos e de produção ou rendimento. As florestas protetoras eram as áreas protegidas de qualquer intervenção humana. Sua função era proteger os cursos d'água, a integridade física e química dos solos, bem como evitar os desmoronamentos de encostas. As coberturas florestais remanescentes eram as áreas com

\footnotetext{
${ }^{16}$ Talvez não seja até os dias atuais, caso contrário não haveria necessidade de um ministério específico para isso, já que a questão ambiental é transversal a todas as áreas ou assuntos de um Estado, assim como a Educação e a Saúde.
} 
características estéticas e biológicas para criação de parques e estações ecológicas. As florestas modelo referiam-se as formações florestais artificiais, ou seja, reflorestamentos para realização de estudos da flora e produção de mudas. O restante das florestas recebeu a classificação de floresta de rendimento. Representavam áreas destinadas ao fornecimento de madeira em escala comercial.

Esta lei não permitia a extração de madeira nas florestas de proteção e somente o corte seletivo nas florestas remanescentes. No entanto, o Código Florestal de 1934 não conseguiu restringir o uso da cobertura vegetal nativa na propriedade privada, pois não previu a conservação de outras formações vegetais diferentes de floresta, além de possibilitar a substituição da cobertura florestal nativa por reflorestamentos com espécies exóticas.

Outra falha contida no texto desta lei posteriormente corrigida no Código Florestal de 1965 relaciona-se a não exigência de cobertura florestal nativa em um quarto de cada propriedade rural. Como o texto da lei fazia menção somente ao ato de desmatamento em três quartos da propriedade, o quarto restante florestado da área original poderia ser desmembrado dela tornando-se uma nova área. Por sua vez a nova propriedade poderia ter três quartos de sua área desmatada. Esta prática possibilitou uma crescente fragmentação dos remanescentes florestais. Geralmente, quando se encontram remanescentes de vegetação deste período nas paisagens atuais é porque tal área não apresenta viabilidade técnica de desenvolvimento da pecuária extensiva ou agricultura convencional.

Drummond (1999) afirma que o Estado não conseguiu intervir de forma efetiva no uso privado da floresta e no uso dos solos agrícolas, pois ficou à deriva da lógica dos proprietários particulares e dos exploradores de terras públicas, de certa forma, protegidos sob o guarda-chuva do arcabouço jurídico da propriedade privada. Curiosamente, tem-se a impressão de que estamos passando atualmente pelo mesmo processo após a aprovação da reforma do Código Florestal de 1965.

O relato do Diretor do Serviço Florestal do Brasil em 1950, professor Vasconcelos Sobrinho, demonstra neste período o conflito instaurado entre a corrente conservacionista e a lógica dos detentores do poder de controlar, vigiar e punir:

O juiz da comarca, o promotor da justiça, o delegado e o comissário, estão sempre prontos em promover a repressão dos delitos comuns [...]. No entanto, os atentados contra a natureza, o esqueleto estrutural do País: a selva, as florestas, o clima, ás águas, aquilo que constitui o meio, o ambiente, onde o povo vive e labora, são desconhecidos, não tidos por delitos e assim, se vê sacrificadas essa outra parte da nação [...]. (PEREIRA, 1950, p. xvii). 
Abaixo segue a opinião do Presidente do Conselho Florestal Federal Luciano Pereira da Silva, que foi relator do anteprojeto do Código Florestal de 1934:

Vínhamos assistindo de braços cruzados à devastação contínua de nossas florestas, apenas com o protesto de algumas vozes que nunca encontraram eco, quer nas esferas governamentais, quer nas particulares, quando entrou em vigôr o Código Florestal no ano de 1934.

Apesar da brandura de suas disposições, de efeito mais educativo do que repressivo, o Código foi recebido, não apenas com indiferença, senão com hostilidade.

A magistratura, à qual o legislador confiou a repressão das infrações florestais, foi a primeira a manifestar a sua repulsa ao novo diploma, absolvendo invariavelmente os que, por lhe infringirem os dispositivos, eram processados, o que importava na paralização completa da ação fiscalizadora, pelo receio de absolvição dos infratores. (PEREIRA, 1950, p. xix).

Osny Duarte Pereira, magistrado que fora convidado pelo instituto Nacional do Pinho para desenvolver a primeira obra acerca do direito florestal brasileiro e que mais tarde viria a ser o coordenador do grupo de cientistas brasileiros responsáveis pela elaboração do Código Florestal de 1965, tece o seguinte comentário sobre a mentalidade dominante da sociedade da época:

No interior, entretanto, cidades importantes são improvisadas de um ano para o outro, com a vinda dos agricultores que abandonam o litoral. As florestas são derrubadas, aproveitam-se algumas árvores para fins industriais e o resto é entregue ao fogo, para limpeza do terreno, onde novas lavouras surgem cobrindo vales e montanhas, numa superfície que excede $o$ alcance da vista. Fotografias magnificas são feitas e publicadas nas principais revistas, como se isto fôsse um trabalho glorioso, os dessas façanhas são apresentados como homens geniais, pelas autoridades e a Nação perdeu mais algumas centenas de quilômetros quadrados do seu território útil, com abandono do solo litorâneo e com a supressão de mais outras centenas de quilômetros de sua área florestal. (PEREIRA, 1950, p. 2).

Em 1962 o Serviço Florestal Federal foi extinto, criando-se o Departamento de Recursos Naturais Renováveis ligado ao Ministério da Agricultura. Em 1964 ocorreu o golpe militar instaurando-se no Brasil um ambiente de mudanças institucionais, desdobrando numa série de reformas de leis, criações de outras etc. Deste modo, por meio da lei no 4.771 de 15 de setembro de 1965 foi instituído o Código Florestal cujo texto traria em 1989, após alteração de parte de sua redação, pela primeira vez o termo sobre a área de Reserva Legal (KENGEN, 2001). 


\section{O Código Florestal de 1965 e a Reserva Legal}

De acordo com Urban (1998), Alceo Magnani relatou que as principais diretrizes na construção do anteprojeto eram apreciar integralmente o Código de 1934 e que o acréscimo de qualquer artigo ocorreria somente por unanimidade entre os cientistas responsáveis na elaboração da nova lei. Contudo, a falta de consenso foi o traço marcante nos debates acerca do estabelecimento das áreas destinadas às florestas protetoras (que assumiriam o termo de preservação permanente no novo código) e das porcentagens de florestas remanescentes a serem conservadas dentro da propriedade rural.

Nas incansáveis discussões relativas às definições das áreas de preservação permanente, Magnani expressou em seu relato a dificuldade em determinar uma regra geral para todo território brasileiro sobre o tamanho da vegetação a ser preservada nas margens dos cursos d'água em virtude da diversidade dos tipos e regimes fluviais, fato este defendido contemporaneamente por vários cientistas acadêmicos brasileiros, por exemplo o professor Aziz Ab'Saber (AB'SABER, 2000, 2003). Segundo Magnani, a equipe também tinha ciência das características da hidrografia brasileira e as relações existentes com as populações que habitavam as margens dos rios e suas práticas agrícolas nas planícies de inundação após a fertilização destes solos pelas cheias naturais.

A despeito das limitações da reserva de floresta em propriedade privada, Alceo Magnani explicou que as indefinições e discussões sobre este tema ocorreram por mais de seis meses até que tiveram de chegar a um consenso, de certa forma, pressionados pelo prazo da entrega do anteprojeto e pelas ordenações do estabelecimento de uma regra geral (URBAN, 1998). Deste episódio, vale transcrever o relato de Magnani:

Um dos participantes mais presentes no grupo, não só pela experiência, mas também pela convicção, foi Henrique Pimenta Vellozo, engenheiro agrônomo e fitogeógrafo que trabalhava em Manguinhos. E ele resolveu assim: "Há um mínimo que deve ser preservado universalmente, seja lá onde o homem esteja, para que haja um certo equilíbrio". E a discussão ficou em torno de qual seria este mínimo: 50\%, 30\% ou 20\%. [...] Quanto mais adverso o ambiente para o homem, tanto maior é a proteção necessária. No Nordeste, por exemplo, 25 \% é pouquíssimo. E fiquei realmente em dúvida a respeito. Foi Henrique Pimenta Vellozo que, um dia, trouxe o artigo dizendo que $80 \%$ podem ser removidos mas, veja bem, excluindo-se as áreas de preservação permanente [...] (URBAN, 1998, p. 231).

No relato exposto acima evidencia-se a existência de uma forte contradição presente na mentalidade acadêmica da época, ou pelo menos em parte de presume-se, justapondo no 
mesmo enunciado um discurso com base ecológica e outro com base econômico utilitarista quando cita "Há um mínimo que deve ser preservado universalmente, seja lá onde o homem esteja, para que haja um certo equilíbrio". Depois transitando para a segunda ideia quando fala: "Quanto mais adverso o ambiente para o homem, tanto maior é a proteção necessária". De qualquer maneira, fica evidente que nas discussões e emergência desta regra de proteção florestal estava instaurada uma lógica conservacionista procurando ainda desgarrar-se da econômica/utilitarista para passar a disputar espaços com ela.

Portanto, a classificação de florestas protetoras foi a base para instituição da APP na Lei 4.771 de 15 de setembro de 1965. As florestas remanescentes e a conservação de $25 \%$ da propriedade rural com vegetação nativa se relacionam à instituição da conservação de vegetação natural ou regenerada dentro da propriedade rural, excetuada a APP, que posteriormente seria intitulada sob o termo de Reserva Legal com a promulgação da Lei 7.803 de 18 de julho de 1989, alterando assim a redação original do Código de 1965.

Atualmente existe um novo Código Florestal, instituído pela lei 12.651 de 25 de maio de 2012, que revogou o de 1965 (BRASIL, 2013). Assim, no que tange a Reserva Legal, a nova lei carrega do Código anterior alguns termos imprecisos em relação à classificação das paisagens, por exemplo "campos gerais". Os outros dois termos, "cerrado e floresta", estão calcados nos conceitos de biomas ou domínios morfoclimáticos, porém "campos gerais" não segue a mesma lógica e, além do mais, na nova lei esta possível feição paisagística é inserida às áreas da Amazônia Legal.

Tal problema envolvendo a conceituação desses termos pode gerar imprecisões também em outro ponto do novo Código: a localização da compensação de passivo ambiental de RL. Na atual lei o conceito de bioma é utilizado para pautar tal procedimento; na anterior, a referência era a bacia hidrográfica.

Além disso, a nova regra permite que a compensação da RL seja efetuada em um estado da federação diferente da localização do passivo ambiental. Na lei anterior, no limite, este ato poderia ser realizado dentro da mesma bacia hidrográfica e, o mais relevante, na mesma unidade da federação da localização do passivo.

\section{CONCLUSÕES}

A instituição do termo Reserva Legal, sua função e importância seguramente podem ser rastreadas até a época do lluminismo, seja por trabalhos científicos ou correntes de 
pensamentos fundamentadas em experimentos ou observações empíricas. Neste sentido destaca-se a influência das teorias climáticas, como expoente a do dessecamento, cunhada na segunda metade do século XVIII relacionando desmatamento às mudanças climáticas.

Pode-se também afirmar que a corrente de pensamento conservacionista, em Portugal por exemplo, com os ensinamentos de Domênico Vandelli, teve seus desdobramentos no Brasil, ressaltando a obra de Alexandre Rodrigues Ferreira que no século XVIII já repreendia o modelo explorador dos recursos naturais amazônicos, além das passagens de importantes naturalistas pelo Brasil ainda no período colonial, dentre eles Charles Darwin, Eugenius Warming, Karl Friedrich Philipp von Martius, August de Saint-Hilaire, Johan Emanuel Pohl. Nesta lógica vale ressaltar os trabalhos dos notáveis José Bonifácio no século XIX e Albert Löefgren no século XX na sedimentação de uma base de cientistas e acadêmicos na corrente conservacionista brasileira. Portanto, desde o início do século passado houve no Brasil um grande esforço científico para a institucionalização de regras de conservação de vegetação natural em áreas públicas e privadas onde tais ações ora eram mais fortes ora enfraquecidas em função das posições ocupadas pelos representantes das classes sociais no seio do poder do Estado, sobretudo dos latifundiários e grandes produtores agrícolas, demonstrando assim a movimentação dessas realidades sociais.

Contudo, uma vez (neste artigo) percebido a evolução da preocupação ambiental no que tange a conservação da Reserva Legal e sua contrapartida científica, espera-se que as classes sociais envolvidas no atual debate passem a unir forças e lutem por uma regra que represente adequadamente a diversidade das paisagens brasileiras, assim deslocando do centro do eixo do pensamento a antiga e atual noção de que uma regra geral com poucos matizes para todo o território possa reger com eficiência a conservação da Reserva Legal nas diferentes propriedades rurais.

\section{REFERÊNCIAS BIBLIOGRÁFICAS}

AB'SABER. A. N. Do Código Florestal para o Código das Biodiversidades: uma exigência da inteligência. Princípios, no 57. p. 74-78, maio/jun/jul 2000.

. Os domínios de natureza no Brasil: potencialidades paisagísticas. São Paulo.: Ateliê Editorial, 2003.

BRASIL, 2013. Lei 12.651 , de 25 de maio de 2012. Dispõe sobre a proteção da vegetação nativa; altera as Leis $n^{\text {os }}$ 6.938, de 31 de agosto de 1981, 9.393, de 19 de dezembro de 1996, e 11.428, de 22 de dezembro de 2006; revoga as Leis $n^{\text {os }} 4.771$, de 15 de setembro de 1965, e 7.754, de 14 de abril de 1989, e a Medida Provisória no 2.166-67, de 24 de agosto de 2001; e dá outras providências. Presidência da República, Casa Civil. Disponível em 
<http://legislacao.planalto.gov.br/legisla/legislacao.nsf/Viw_Identificacao/lei\%2012.651-

2012?OpenDocument>. Acesso em 02 de maio de 2013.

ACOT, P. A natureza da humanidade. Revista Ciência \& Ambiente, Santa Maria, v. 5, (III), p. 7-17, jul/dez 1992.

O Brasil e a constituição da ecologia científica no século XIX. Revista Ciência \& Ambiente, no 13. p. 7-14, jul/dez 1996.

CARVALHO, E. B. de. Legislação Florestal, território e Modernização: O caso do Paraná, 1907 - 1960. In: Simpósio Nacional de História, 24, 2007. São Leopoldo. Anais do XXIV Simpósio Nacional de História. História e Multidisciplinaridade: Territórios e deslocamentos, 2007. São Leopoldo: Associação Nacional dos Professores Universitários de História, 10 p.

CASATTI, L. Changes in the Brazilian Forest Code: potential impacts on the ichthyofauna. Biota Neotrópica, Campinas, v. 10, no. 4, p. 31-34, 2010. Disponível em: <http://www.biotaneotropica.org.br/v10n4/en/abstract?article+bn00310042010>.

DEAN, W. A ferro e fogo: A história e a devastação da Mata Atlântica Brasileira. Tradução Cid Knipel Moreira. São Paulo: Companhia das letras,1996, 484 p.

DEVELEY, P.F. \& PONGILUPPI, T. Potential impacts of the changes proposed in the Brazilian Forest Code on birds. Biota Neotrópica. Campinas, v. 10, no 4, p. 43-45, 2010. Disponível em: <http://www.biotaneotropica.org.br/v10n4/en/abstract?article+bn00610042010>.

DRUMMOND, J. A. A legislação ambiental brasileira de 1934 a 1988: comentários de um cientista ambiental simpático ao conservacionismo. Revista Ciência \& Ambiente, no 3 e 4. p. 127-149, 1998/1999.

GALETTI, M. et al., C.A. Forest legislative changes and their impacts on mammal ecology and diversity in Brazil. Biota Neotrópica. Campinas, v. 10, no 4, p. 47-52, 2010. Disponível em: <http://www.biotaneotropica.org.br/v10n4/en/abstract?article+bn00710042010>.

GROVE, R. H. Green imperialism. Colonial expansion, tropical islands Edens and the origins of environmentalism, 1600 - 1860. Cambridge; New York : Cambridge University Press,1995, $540 \mathrm{p}$.

KENGEN, S. A política florestal brasileira: uma perspectiva histórica. In: Simpósio IberoAmericano de Gestão e Economia Florestal, 1, 2001. Porto Seguro. Anais do 10 Simpósio Ibero-Americano de Gestão e Economia Florestal, 2001. Porto Seguro: Série Técnica Instituto de Pesquisas Florestais, no 34, 2001. p.18-34.

LEÃO, R. M. A floresta e o homem. São Paulo: Editora da Universidade de São Paulo: Instituto de Pesquisas Florestais, 2000. 434 p.

LÖEFGREN, A. Contribuição para a questão florestal da região nordeste do Brazil. Rio de Janeiro: Imprensa Ingleza, 1923, $131 \mathrm{p}$.

Serviço florestal de particulares. São Paulo: Typografia do Diario official, 1903, 33 p.

MAGALHÃES, J. P. A evolução do direito ambiental no Brasil. 2a edição. São Paulo: Editora Juarez de Oliveira, 2002. 76 p. 
MAHAR, D. J. Government policies and deforestation in Brazil's Amazon Region. Washington, D.C. World Bank, 1989. 56 p.

MEDEIROS, R. Evolução das tipologias e categorias de área protegidas no Brasil. Ambiente \& Sociedade, Campinas, v. IX, n. 1, p. 41-64. 2006

MENEZES, D. Proudhon, Hegel e a dialética. Rio de Janeiro: Zahar Editores, 1966. 49-80p.

METZGER, J. P. Efeitos do padrão de desmatamento e da extensão de Reservas Legais na conservação florestal em áreas de assentamento da Amazônia Brasileira. Biota Neotrópica, Campinas, v. 1, n. 1/2, p. 17-30, 2001.

. O Código Florestal tem base científica? Natureza \& Conservação 8(1) p. 1-8, 2010.

PÁDUA, J. A. Arrastados por uma cega avareza: As origens da crítica à destruição dos recursos naturais amazônicos. Revista Ciência \& Ambiente. Santa Maria, no 31, p. 133-146, jul/dez 2005.

PARDINI R et al. Beyond the Fragmentation Threshold Hypothesis: Regime Shifts in Biodiversity Across Fragmented Landscapes. PLoS ONE 5(10): e13666 doi:10.1371/journal.pone.0013666. 2010.

PEREIRA, O. D. Direito florestal brasileiro: ensaios. Rio de Janeiro: Borsoi, 1950, 573 p.

POULANTZAS, N. Poder político e classes sociais do Estado capitalista. Tradução de Francisco Silva. Porto: Portucalense, v. 1, 1971. 221 p.

ROUGERIE, G; BEROUTCHACHVILI, N. L. Géosystèmes et paysages. Bilan et méthodes. Paris: Armand Colin, p. 125-261. 1991.

RIBEIRO, K.T. \& FREITAS, L. Potential impacts of changes to Brazilian Forest Code in campos rupestres and campos de altitude. Biota Neotrópica. Campinas, v. 10, n.4, p. 239-246, 2010. Disponível

em:

<http://www.biotaneotropica.org.br/v10n4/en/abstract?article+bn04310042010>.

ROCHA, H. R. da. Vegetation-atmosphere interaction study for Amazônia deforestation using field data and single column model. Quaterly Journal of the Royal Society, London, v. 122, n. 531, p. 567-594, 1996.

SWIOKLO, M. T. Legislação Florestal; evolução e avaliação. In: Congresso Florestal Brasileiro, 6, 1990, Campos do Jordão. Anais do 6 Congresso Florestal Brasileiro, Florestas e Meio Ambiente: Conservação e produção, Patrimônio Social. v. 3. Campos de Jordão, São Paulo: Sociedade Brasileira de Silvicultura; Sociedade Brasileira de Engenheiros Florestais, 1990. v. 3. p. 53-58.

URBAN, T. Saudade do matão: relembrando a história da conservação da natureza no Brasil. Curitiba: Editora da Universidade Federal do Paraná, 1998. 374 p.

SANTIAGO, A. V. Simulação dos efeitos da cobertura vegetal no balanço hídrico da bacia do rio Ji-Paraná. 2005. 69 f. Tese (Doutorado em Agronomia) Área de concentração: Física do Ambiente Agrícola. Escola Superior de Agricultura "Luiz de Queiróz", Universidade de São Paulo, Piracicaba, 2005. 
SMOUTS, M. C. Tropical Forests International Jungle: The underside of Global Ecopolitics. Translated by Cynthia Schoch. New York: Palgrave Macmillan, 2003, 266 p.

WHITMORE, T. C.; SAYER, J. A. "Deforestation and species extinction in tropical moist forests. In: WHITMORE, T. C.; SAYER, J. A. Tropical deforestation and especies extiction. London; New York: Chapman \& Hall, 1992. 147 p.

Artigo recebido em 10/04/2013.

Artigo aceito em 04/05/2013. 